\title{
Online Personal Learning Networks for Older Adults: Impacts on Social and Mental Well-Being
}

\author{
Dirk Morrison \\ University of Saskatchewan
}

Received: March 13, 2020

Accepted: May 8, 2020

Published: May 8, 2020

doi:10.5296/jse.v10i2.16600

URL: https://doi.org/10.5296/jse.v10i2.16600

\begin{abstract}
This study investigated retired older adults (age 55+) who use the Internet to facilitate their informal, self-directed learning by creating and maintaining their online personal learning networks (oPLNs), and how such use impacts their personal, social, and mental well-being. Guiding this examination were particular research questions that specifically queried the perceived value of their oPLNs to activate and self-direct their informal learning. The web-conferencing tool WebEx was used to conduct four synchronous online focus groups allowing a total of 15 voluntary, geographically dispersed participants from across Canada to share their experiences and insights. A thematic analysis of the focus group transcripts revealed themes informing how oPLNs facilitated their informal learning goals and influenced participants' personal valuing of their online activity. As a component of results from the larger research study (Morrison, Litchenwald, \& Krystkowiak, 2020; Morrison, Litchewald, \& Tang, 2020; Morrison \& McCutcheon, 2019) , the findings presented, drawn from the online focus group qualitative data, indicated positive perceived valuing of their informal learning via their oPLNs as well as indications of favorable social and mental well-being outcomes. Interpretive speculation is provided regarding how these informal online learning experiences and oPLNs in particular, may point to a favorable impact on similar retired older adults' personal, social, and mental well-being.
\end{abstract}

Keywords: online personal learning networks, older adults; informal learning, self-directed learning, older adults' well-being, mental well-being 


\section{Introduction}

A clear demographic trend, derived from global census data, posits that the percentage of older adults (age 60 and older) will continue to rise in developed countries from $22 \%$ of the population in 2010 to $29 \%$ by 2030 (World Economic Forum, 2012); this trend is mirrored in the Canadian context, with predictions indicating that by $203023.6 \%$ of the population will be over the age of 65, an increase of almost 10\% from 2013 Census Data (CBC News, 2014; Kembhavi, 2012). Accompanying these demographic shifts are some sobering implications for society, including potentially diminished quality of life (Golden, 2009; Cornwell, 2009) for a large portion of the population and increased demands on human services. It follows that an important consideration for any society facing such challenges will be to identify and understand factors that favourably impact the personal, social, and mental well-being of older adults (Pike, 2011; Hare, 2014). While successful aging is multidimensional, the research is clear: maintenance of high cognitive function, sustained social engagement, and the pursuit of meaningful activities are essential factors that contribute to psychological and social well-being as we age (Rowe \& Kahn, 1997; Glass, et al, 2006).

Notably, informal, self-directed lifelong learning provides an effective conduit and practical conceptual framework to achieve personal, social, and mental well-being. Merriam and Kee (2014) claim "learning in older adulthood not only reduces dependency on government-funded social services but actually enhances personal and community wellbeing" (p. 133). Field (2009) reported evidence that indicates lifelong learning activities are "particularly effective in enhancing the wellbeing of our most vulnerable citizens, [including] older men and women" (p. 36). While evidence exists linking lifelong learning to increases in both human and social capital (Balatti \& Falk, 2002), it is not well understood how older adults use the Internet and social media tools to become not only more knowledgeable, but also, increasingly, cognitively and socially engaged. Specifically, we have little discernment regarding how older adults have transitioned to using these technologies to extend their engagement within informal, self-directed online learning environments. Accordingly, this research explored how older adults used a variety of Internet-based and social media tools to create and maintain personal learning networks (oPLNs) online to support their lifelong learning purposes (Morrison \& McCutcheon, 2019). A core set of our study results was the generation of concrete evidence for the claim that this demographic, through active engagement with others in online personal learning networks (oPLNs), provided an "ecology of learning" that contributed to their personal, social, and mental well-being.

Within the context of the wider exploration of informal, self-directed learning through oPLNs, this unique and understudied demographic (i.e., retired older adults) was specifically targeted due to the assumptions that their desire to informally learn was driven by intrinsic motivation factors; the corollary is that we can reasonably assume older retired adults, freely pursuing their hobby or interest, are not doing so for extrinsic or instrumental reasons (e.g., career advancement), but, rather, for personal, intrinsically-motivated reasons Finally, informal, self-directed learning of this type can be contrasted with formal learning because it does not assume traditional role differentiation (student/teacher; the teacher as the resident expert, etc.); 
rather, in this study, "experts" within informal learning ecosystems like an oPLN, may emerge within a dynamic and fluid identity allocation process. This, in turn, provided for evidence of a shared cognition, or thinking as social practice (Resnick, 1991).

The growth of the older adult demographic, as a global phenomenon, coupled with the knowledge gap regarding older adult informal learning, in-turn conjoined with ever advancing digital information and communication technologies (ICTs) makes this study of oPLNs a significant and timely contribution to deepening our understanding of how and why older adults leverage the power of ICT tools, contexts and processes for the purposes of informal knowledge acquisition and personal transformation was the primary goal of this research. Specifically, the research investigated how older adults expand and enrich informal, self-directed lifelong learning goals via the creation, expansion and engagement of their online personal learning networks (oPLNs) and how this objective may, in turn, have impacted their perceived social and psychological well-being.

\section{Literature Review}

\subsection{Older Adults' Informal Online Learning}

While it is true our concept of lifelong learning for older adults needs to incorporate all types of learning (i.e., formal, non-formal and informal), Merriam \& Bierema (2014) indicate that "most adult learning is through non-formal and informal means" (p. 138). Non-formal learning includes structured but non-credentialed educational events or programs sponsored by community, civic, and voluntary organizations. Informal learning is that which occurs in one's day-to-day living, and may include incidental learning (i.e., serendipitous learning). However, this study is aligned with Merriam and Kee (2014) who focused on informal learning as a more systematic set of self-directed learning activities where a person designs and executes his or her own "learning project" with personal goals and outcomes in mind. The older adults in this study methodically pursued a wide range of learning goals (e.g., health and wellness, leisure, personal interests, computer and media literacy, etc.) via informal and self-directed processes.

\subsection{Older Adults'Informal Online Learning: General Benefits}

Contrary to stereotypical perceptions of this phase of life, the majority of older adults are healthier, more economically independent, increasingly "computer-savvy", and often actively pursuing lifelong learning opportunities to enhance and "make meaning" of their lives (Fisher \& Wolf, 2000; Kembhavi, 2012; Sadler \& Krefft, 2008; Seals, et al, 2008). Dench and Regan (2000), investigating the non-economic impact of learning for older adults, found that key reasons given for engaging in informal, self-directed learning activities were intellectual and socio-psychological: learners reported wanting to "increase their knowledge, keep their brains active, enjoy the challenge of learning new things and learn about something they had always been interested in and for personal satisfaction" (p. 1). An additional pertinent finding was that 80 percent of participants reported the positive impact of informal learning on at least one of the following areas: "enjoyment of life; self-confidence; self-esteem; satisfaction with other areas of life; and, their ability to cope with life" (p. 4). While such evidence is 
encouraging regarding the potential impact of informal, self-directed learning on older adults' mental, physical and social well-being, what is missing from our current understanding is how older adults use ICTs, specifically the Internet and Web 2.0 social media tools, to mediate their lifelong learning goals and outcomes. It is clear that ICTs have had and continue to have an enormous impact on society, including how we live, work, create, communicate, and connect with others; much has been investigated regarding how we can harness these ICT tools and processes for learning (Sutherland et al., 2004; Castaneda \& Soto, 2010; Hernandez et al., 2011). However, the vast majority of these research efforts focused on children, youth, and career-age adults (Alexander, 2006; Greenhow, Robella \& Hughes, 2009; Subrahmanyam, 2008); conversely, there is a paucity of research regarding older adult learners' adoption and adaptation of Internet-based learning resources, tools, and processes in support of informal, self-directed lifelong learning goals. Field (2000) warns us to not neglect such groups, risking exclusion, inequalities, and erosion of human capital, and argues that we must embrace a widening participation in a learning society.

\subsection{Older Adults' Informal Online Learning: Social and Psychological Benefits}

Social isolation and loneliness are clearly significant risk factors with potential to affect not only mental and social well-being, but physical health as well (Luo et al., 2012; Cacioppo \& Cacioppo, 2018). Focused on promoting older adults' well-being through Internet training and use, Shapira, Barak, and Gal (2007) concluded that "Computer and Internet use seems to contribute to older adults' well-being and sense of empowerment by affecting their interpersonal interactions, promoting their cognitive functioning, and contributing to their experience of control and independence" (p. 477). Further, in a rare paper examining older adults' use of informal online learning and its relation to life satisfaction, Dorin (2007) claims that "...older adults' life satisfaction is positively impacted by even minimal exposure to online education" (p. 127); the author defines life satisfaction as reflecting the overall well-being of an individual, to include: physical and mental health, socioeconomic status, and education. Examining Internet use and the phenomenon of loneliness in older adults, Sum, Mathews, Hughes, and Campbell (2008) found that "analyses revealed that greater use of the Internet as a communication tool was associated with a lower level of social loneliness" ( $\mathrm{p}$. 208). Hernández-Encuentra, H., Pousada, M. and Gómez-Zúñiga, B. (2009) extend the details of this claim by stating that "Older people's adoption of IT needs to be treated as more than merely a question of usability. Attitudes, experience of use, and perceived benefits are also key aspects that must be taken into account” (p. 226). Finally, Sum, Matthews, Pourghasem and Hughes (2008) in an investigation of Internet use as a predictor of a sense of community in older people found that "there was a positive association between a sense of belonging to an online community, sense of community, and well-being" (p. 225). While such studies propel our general knowledge regarding potential benefits of ICT use amongst older adults, there is no literature specifically investigating older adults' use of the Internet to create informal online personal networks (oPLNs) and the effects this might have on mental and social well-being. This study addresses the striking gap in our collective understanding of the potential of these communication technologies and processes to enrich the lives of older adults, presenting significant findings regarding the possible link between activity in informal, 
self-directed learning within an online community and the potential for such to have positive personal, social, and mental well-being impacts.

\subsection{Theoretical Interpretive Frameworks}

This exploratory research necessarily draws upon a variety of theoretical constructs, conceptual frameworks, and application contexts for the purposes of interpretation. Given the older adult demographic of this study, the utility of adult learning theory (Baumgartner, 2001; Knowles et al., 2011) as a general conceptual framework is obvious. To add further power to the analyses and interpretation of the data presented, given the self-directed and engaged nature of these older adults' technology-enhanced learning activities, the complementary theories of networked learning theory (Asensio, et al., 2000) and heutagogy (Blaschke, 2012; Blaschke \& Hase, 2016) are valued conceptual frameworks guiding our interpretations of the findings.

\section{Methodology}

The following presents the research methodology, methods, and procedures, activated for organizing, coding, and analyzing the transcribed data from four synchronous online focus groups and four individual audio interviews collected for this study (further details of this methodology are presented in Morrison, et al, 2020).

Phase I of the research included the distribution of a national survey to 385 older adults regarding their use of ICTs to construct, develop and maintain online personal learning networks to facilitate their informal, self-directed learning activities; these participants were recruited from a database provided by Probit ${ }^{\mathrm{TM}}$ Inc. and all Canadian Provinces were represented. Upon completing the survey, participants were afforded the option of volunteering to engage in Phase II, namely, online focus groups (using the web-conferencing tool, WebEx); a total of 15 agreed to participate, with 11 spread across four focus groups and four agreeing to participate via a one-to-one telephone interviews. All sessions were facilitated by staff trained in conducting focus groups and all were audio recorded; transcripts of all interviews were generated and provided the raw data necessary for further qualitative analyses.

Following data collection, a thematic analysis of the online personal learning network (oPLNs) focus groups and one-on-one interviews data was conducted. A descriptive phase was completed, based on a codebook set of a priori categories established by the research team; the predefined coding framework was created to guide the first round of descriptive coding to focus the analysis on the research study objectives. Four individual trained coders worked with a subset of the data to establish reliability through intercoder agreement. Finally, the analytical and interpretative phase from which themes were created involved the process of iteratively and collectively (i.e., all team members contributed to the process), defining and redefining themes. Next, the a priori categories were reviewed and edited by the research team to develop the final codebook that would guide the coding analyses completed by four independent coders; all used NVivo Pro ${ }^{\mathrm{TM}}$ as the qualitative software analysis program to complete the coding of all transcripts. Coding comparison queries revealed an established 


\section{MlMacrothink}

'good' intercoder reliability (i.e., Kappa coefficients of 0.4 or above) (Kraemer, 2015). A few categories were revisited to achieve greater alignment in coding construct; this refinement was important to achieve higher intercoder agreement on all text segments. As a result of this iterative process, some codes were collapsed into broader themes, while others were delineated into their own, unique sub-themes; this was deemed necessary to achieve refinement (i.e., robustness, parsimony) among and between coding categories and definitions. Each team member then re-coded the transcripts for this coding subset, based on the modified and standardized definitions, followed by inter-coder agreement queries to calculate kappa coefficient intercoder reliability statistics; with this coding refinement, we achieved a higher percentage of agreed upon codes for the themes identified (i.e., Kappa coefficients indicating reliability of 0.5 or higher).

For the transcript coding process, a contextual thematic analysis approach (Nowell, Norris, \& White, 2017) was taken to ensure resulting analyses acknowledged participants' experiences in an inductive or data-driven manner, but also took into consideration the wider social context in a deductive or theoretical view; this approach, in line with Braun and Clarke (2006), is also reflected in the variety of excerpts presented and concomitant discussions. Overall, the thematic analysis process was iterative and dynamic, achieving relative saturation of themes in two stages: 1) descriptive coding, which focused on semantic meanings presented by participants, followed by 2) analytic coding which focused on organizing higher-level themes based on more latent meanings from the resultant descriptive themes. Because the analysis approach taken permits multi-coding, it should be noted that excerpts provided in one theme may also be applicable and convey representation within other themes in the findings.

\section{Findings and Discussion}

The thematic analysis resulted in a complex matrix of multiple themes and sub-themes; however, only those of relevance to our discussion here, namely, those related to social and mental health impacts of online learning are reported below. Presentations of the findings, including verbatim illustrative excerpts, are conjoined with a brief discussion of each theme viewed through the interpretive "lenses" of the theoretical frameworks. Figure 1 below outlines the relevant thematic elements and findings structure of the following sections: 

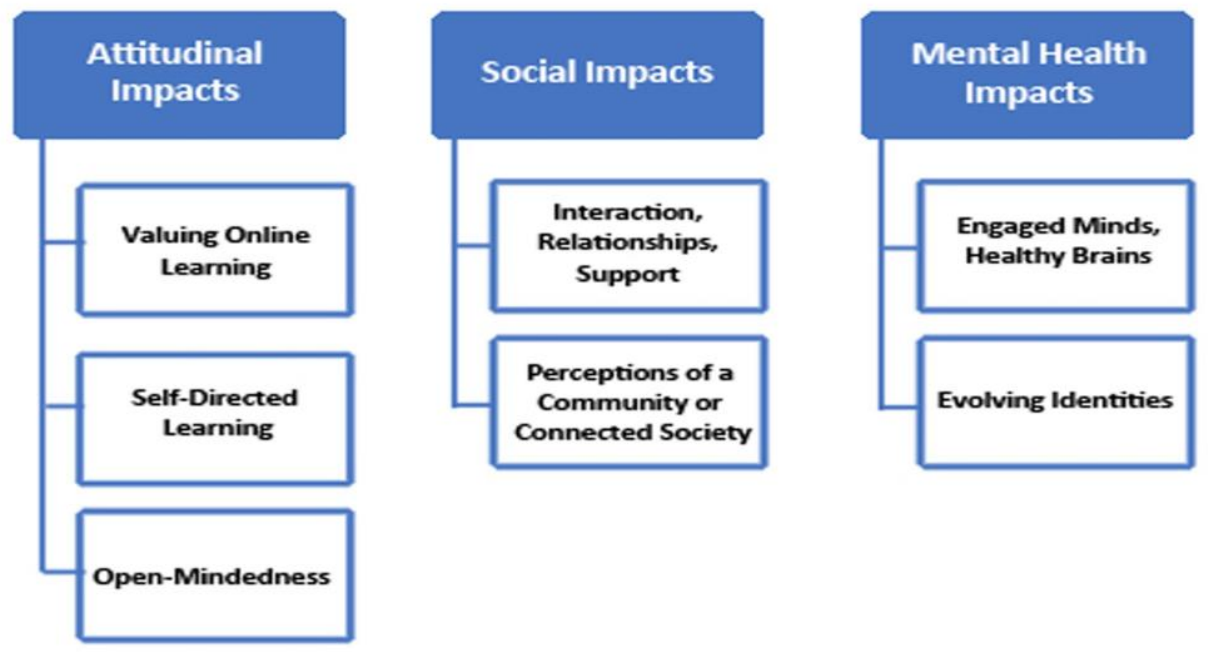

Figure 1. Major themes and sub-themes

\subsection{Attitudinal Impacts of Online Learning}

The following section presents participants' descriptions regarding shifts in personal perspectives and attitudes via their experiences learning online within their oPLNs. These shifts consider value-based perceptions of online learning, self-directed learning, and the practice of being and becoming open-minded.

\subsubsection{Valuing online learning}

Among the impacts resulting from their oPLN engagements, some participants described their online learning as advantageous for informal learning in regard to convenience, effort, and efficiency. For example, participants said that accessing their oPLNs was more convenient and expedient when seeking information focused on a specific topic, illustrated in the excerpt below:

I'd certainly start there [with online resources] because it is a very easy, low cost, low effort way of finding out more about any topic. (Focus Group \#1, Participant \#1)

When participants were probed to consider dynamically engagin with and learning from others in their oPLNs, the technological affordances of the online tools and contexts was made obvious by the following participant's comment:

[I] t's very convenient to be able to shoot your friends and fellow watercolorists one or two things that you do that illustrate what you're talking about. The ability to see a picture that 
you can photograph and stick online.... a lot of the time it's easier to contact each other by email, but not lose sight of what each other's doing. (Focus Group \#3, Participant \#1)

Similarly, the excerpt below shows a participant pointing to the process of "curating" information for credibility and utility - a significant example of digital literacy processes in action:

The other way I look at it is that, if I didn't have this online, what would be the resources that'd be available for me? It'd be nowhere near as comprehensive, and so I'm happy to spend a little bit of time narrowing things down, weeding things down, getting information for the fact that the wealth of information that I'm going to get as a result will probably be very credible and very useful information.

(Focus Group \#1, Participant \#1)

\subsubsection{Self-directed learning}

Another point of interest is the articulation of the core attitudinal value of being self-directed in one's learning by the majority of participants. As one participant noted:

I really like it because it makes me more independent as a learner, but I also limit what I look at to learn. (Interview \#5 Participant)

Regarded with a "sense of freedom" in one's learning enterprise, being in control of one's own learning, including the paths and processes, enriches our conceptual understanding of "connected autonomy" in online informal online learning contexts with older adults. Moreover, many contrasted this form of learning with traditional methods as showcased by the following excerpts:

I realized that you didn't have to learn things about music particularly playing digital music, all by yourself locked up in a room or studying or one on one with a teacher who is physically present with you. But you could actually access resources that are enormous potential online. (Focus Group \#4, Participant \#3)

Ultimately, I was quite disgusted with [the formal course] because it wasn't giving me what I needed and I was coming home and getting the real knowledge online.

(Interview \#5 Participant)

The fact that the creation and ongoing development of oPLNs is, by its very nature, a self-directed activity (i.e., one decides what and whom to include, when it is accessed, and for what purposes, etc.) aligns these findings with earlier work underscoring the centrality of self-directedness within informal learning contexts and processes (Brookfield, 1985; Candy, 1991; Garrison, 1997; Merriam, 2001; Marskick \& Watkins, 2002).

\subsubsection{Open-mindedness}

A recurrent sentiment expressed by a number of participants is that their oPLNs were learning spaces in which they felt "safe" expressing alternate or contrary ideas and opinions. One participant even discussed the openness of others to be almost like a prerequisite: 


\section{MlMacrothink}

Journal of Studies in Education

ISSN 2162-6952

2020, Vol. 10, No. 2

[Y]ou have to be relatively open-minded. [...] Too many people aren't. Their minds are closed. They want to hear what they want to hear. (Interview \#4 Participant)

These self-reported perceptions of the nature of these online communities revealed an attitudinal impact, one where trust and respect for others was an embedded value:

I find that you normally get to share common experiences and common perspectives but, as you develop a sense of trust in a particular community that you're dealing with you can then find out that you don't have to agree on a lot of things and you can actually increase your degree of respect for difference of opinion or viewpoint on things. And that for me is a really good place to try and get to in terms of your learning program and the way you deal with your - I guess personal learning networks. That's a sign of maturity. (Focus Group \#4, Participant \#3)

As the above excerpt describes, a benefit of establishing a safe and supportive online environment exists in at least some of these oPLNs, where debate, questioning, and exchanges of various perspectives is valued and encouraged. Moreover, some members claimed that this attribute from their oPLN engagements had a positive growth effect on their level of "open-mindedness." Evidently, these personal interactions with others in their oPLNs may often lead to changes in attitude, especially around openness to others' ideas and viewpoints. One participant described this as increasing "your degree of respect for difference of opinion or viewpoint on things." Another described a "cultural shift" occurring whereby "being part of specific groups (e.g., religious) doesn't matter when everyone comes together in these learning communities." Some participants also described changes in specific intrinsic and extrinsic behaviours such as increased assertiveness and self-reliance. These attitudinal changes, in turn, then led to some individuals to feel "more in control" of their learning. Furthermore, a connection was made between the value of open-mindedness and mutual support impacts identified (i.e., cooperation, helping others, reduced social isolation), as illustrated by the following excerpt:

It does allow me to respond and help other people which is important to me. It allows me to cooperate with these other people- these other seniors. It helps us to provide a real place for senior women who otherwise might be much more isolated. It's high quality. [...], there is a very real advantage in coming together as a group and exploring ideas which increasingly interfaces with the internet and stuff that's out on the internet. I think it's really positive for these women. (Interview \#3 Participant)

Of special interest here is our speculation that feeling comfortable and safe within their oPLN, where the "group norm" was to support open-minded exploration of ideas, issues, and content, contributed to participants' sense of autonomy, self-worth, and self-efficacy. For example, if one's opinion and perspectives on an issue are respectfully considered and valued by one's peers, it is logical that reticence to share these for fear of ridicule will be reduced; the corollary of this is an increased sense of "equality among peers" and a sense of security in the collaborative online learning environment. These forms of interaction and exchange are, in our view, necessary prerequisites and constituents for what Meizirow (2012) calls transformative learning experiences, a "constructivist" orientation to interpret and reinterpret 
experience, a core cognitive process central to meaning making and hence learning (Mezirow, 1991). The aforementioned evidence describing an authentic, active and supportive learning network wherein "open-mindedness" is encouraged and fortified, provides confidence that these learning networks have the potential to facilitate transformative learner experiences. This online "safe space" where effective engagement with other learners can take place is the antecedent for establishing a thriving "learning ecology" where active and "evolving" learning is the norm (Jaramillo, 1996). Illustrating the reciprocal and dynamic nature of information exchanges taking place within their oPLNs, many reported this as not only a source of new information regarding the focus of their informal learning but also that activity in their oPLNs expanded their views and understandings through these interactions; this linking of people's diverse experiences allowed for an enhancement of the learning process that might not be possible in a different context (e.g. offline, classroom-based learning). In addition, learning with and from others offers not only "knowledge scaffolding" (Sharma \& Hannafin, 2007), but also support encouragements and mentorship. For example, the following excerpts illustrate not only general tools and strategies for knowledge acquisition but also the valuing of interpersonal communications in their oPLNs as sources of support for learning.

$[M] y$ involvement with it has broadened and deepened my appreciation for a particular learning situation [...] They're very good at picking up on the things that you're interested in, that you focus on...And I find that when I talk with other people in the online forums and so forth, when they're looking for information they find different information than I find. And so having that personal connection where you're talking to somebody on a particular topic, and they will have found things different than I will find things, and I find that very, very useful.

(Focus Group \#1, Participant \#1)

\subsection{Social Impacts}

While attitudes guided the first layer of our exploration of valuing online, informal self directed learning, we were interested in a deeper examination of participants' individual perceived personal impacts as a result of their online learning activities. Given the deleterious effects of social isolation or lack of personal interaction with others on the mental and physical health of older adults (Bassuk, Glass, \& Berkman, 1999), such aspects of individual or person-level impacts are of central importance to our discussion here.

\subsubsection{Interaction, relationships and support}

Analyses of the transcripts discovered the perceived positive benefits of the levels of personal interaction experienced by the participants. Many discussed the tangible outcome (impact) of engaging in their oPLN's as having a sense of connection and a general desire to further their relationships with others:

"T] here's a real sense of camaraderie developing there. There's a great sense of camaraderie amongst the e-toys group. Again, people often come very sort of nervous to do that and very quickly get integrated." (Focus Group \#3, Participant \#2) 
Some participants talked about how being involved in their online learning networks lead to the "ability to develop relationships you would otherwise not have access to or become aware of." Specific to the idea of building relationships was the enhanced opportunity for long-distance associations and direct correspondence with others. It is clear that these online relationships would not be realized without access to the Internet, and they offer something more than local relationships might:

[T]hat for me has been the big enriching part of going online. I mean absolutely you can go to a coffee shop and meet people or take a course in your local environment and get to know people but, being able to do that online obviously extends your reach potentially enormously. Now I can - would consider to be friends from different parts certainly in North America that I never would have met had I not pursued my personal learning interests and found out that we have some things in common, and we had more things in common beyond the things that we were trying to get out of our personal learning approaches.

(Focus Group \#4, Participant \#3)

The other thing that I find very useful about online learning is about the fact that you can connect with people that you might never run into otherwise. [...] You might have 20 people in the world that are interested in this, and so with the online community, you will make those connections that otherwise you just won't make connections when you're in any urban setting. You might not find anybody who has that particular interest. So that's where I find the online community is going to be extremely, extremely powerful. (Focus Group \#1, Participant \#1)

So, while accessing reliable content was the initial motivator for participants to create and use their oPLNs, developing relationships appears to be an unanticipated favourable result for many participants. In other words, the activity in participants' oPLNs may offer more connections because of the mutual interest in the topic but ultimately, this interaction, in turn, may lead to the pursuit and development of interpersonal relationships and a sense of interdependence. As one participant illustrated:

I'd say it's both but sometimes it's a two-street process. But I think you might - well for sometimes I can think of situations where I've started off by thinking, 'Well I just need to fill this particular information gap', and then when the other parties started contributing things and I look at them and I think, 'Well just a minute. I'd like to know these people more. (Focus Group \#3, Participant \#1)

A core affordance of networked learning, then, is the ability to connect with others in meaningful ways and focus around common informal learning interests:

I've built a network of individuals over the years probably that I correspond with more often than others. It gives me a - it's a kind of a warm and fuzzy feeling to know that I've got people that are interested in the same thing as me, and are willing to help out when I have a question....it's kind of like a support network that I've developed over the years, I find it very helpful.

(Focus Group \#4, Participant \#2) 
It is clear from our findings that oPLNs offered more than just informal learning opportunities - they became an informal learning support network for the individuals. In fact, for some, over time, learning seems to have taken a "back seat" to the sustained community aspects of their oPLNs. Expanding on the reported value of support to achieve their learning goals, the role of oPLN members as sources of mutual support was specifically identified by a number of participants. The following are examples of the basic sentiment of support in learning, facilitated by interpersonal interactions within their oPLNs:

Very little things like this, you have to have demonstrated to you by people who are encouraging and just enough authority and a lot of encouragement. (Focus Group \#3, Participant \#1)

I feel more supported [...] and challenged by the online people that I've met that are all at a much higher level than I am but are very supportive of me and encouraging. (Focus Group \#2, Participant \#1)

This actualized attitude of perceiving others as supporters of their individual, online learning processes is, in our opinion, a pivotal constituent in any thriving oPLN; if peer connections are absent, the entire system is at risk of collapse due to an eroding perception of the value of human support within that learning environment. The centrality of this very human value/need, found here within these online learning environments, has been well-documented within formal education settings (Garrison \& Arbaugh, 2007), identified by some as "social presence" (Gunawardena, 1995; Tu, 2000); it is, therefore, encouraging to observe a similar emphasis in our informal, online learning context of oPLNs.

\subsubsection{Perceptions of a connected community of learners}

Expanding from the individual to the collective, this sub-theme presents how participants expressed their perceptions of a learning community resulting from activity within their oPLNs. Participants emphasized a re-defining of the word "community"; the ability of ICT-based entities like an oPLN to span borders, time-zones, geopolitical domains, rural/urban and remote locations, together were identified as different and powerful catalyst for redefining the term "community," moving from the parochial and local to the more global concept of an "ecology" of learning. This expansion of definition and articulation in learning networks is not new, but it is interesting to observe such as perceived by these older adult learners.

The social interaction that takes place within these online communities manifests a greater meaning and ultimately a deeper form of interconnectedness:

I think it's bigger than that [online interaction] it helps to build on a different sense of the word community across borders that we badly need in our world...I think that every network that we create that crosses borders, helps us as a world as global community [...] reducing a sense of divide we have between rural/urban, and remote or isolated, name your term. I think it'll help us understand each other's issues far better than we have any hope of doing right 
now. (Focus Group \#4, Participant \#1)

This sense of "a connected society" or community was a repeated concept perceived to have had great value in participants' sense of well-being and association with other like-minded individuals. As one participant describes:

The importance of having the tools such as the Internet, to being able to achieve some of those aims, the potential real value that you get out of doing those things to creating a - what I guess we locally or not would say, is a connected society. (Focus Group \#4, Participant \#3)

Respectively, the conviction that online learning communities were established and that participants actively engaged with members of those communities cannot be underestimated in its potential to contribute to one's well-being. Lubben and Gironda's (2003) meta-analysis of the centrality of social ties to the health and well-being of older adults claims: "...because public health experts posit that the association between social support networks and health is now as strong as the epidemiological evidence linking smoking and health" (p. 320); it is, therefore, vital to examine how social ties might "increase active life expectancy and improve the quality of life among older adults" (p. 319).

Clearly, all of the above online learning activity is of reduced value unless there is a concrete set of associated impacts or outcomes. Our findings clearly identified both individual or personal impacts, but also discovered perceptions of impact on the learning community, or the "connected society," in miniature. For example, the fact that oPLNs, especially those network nodes with a long history and value addition (i.e., facilitated the development of interpersonal relationships, keeping in touch with others, and a sense of being supported within community), had a clear personal impact for many. Also identified were impacts on attitude and behaviour changes, to include perceived mental health benefits as a result of their activity within their oPLNs.

\subsection{Mental Health Impacts}

A surprising finding was that many participants reported social learning activities in their oPLNs as having a positive impact on their mental health. Regarding the positive effects of learning via their oPLNs on social and mental well-being, participants talked about an internal urge/desire to constantly be learning something new. Being "open to new things," and "pushing the envelope of awareness," within the area of personal growth and development were themes regularly identified as core to participants' motivation to participate in their oPLN's:

I think all of us are motivated from that we're trying to push the envelope of our awareness, our area of - not our area of expertise but our own growth and knowledge of particular content area. (Focus Group \#4, Participant \#1)

Being informed and keeping up with emerging trends in the "social milieu" was also deemed important to participants. They discussed "keeping up with the times" (e.g., attitudes, social conditions), a desire to have "a more informed debate", and being "personally informed" about individual lifestyle (e.g., learning about medical prescriptions). Finally, staying 
"up-to-date" was a consistent resonant theme, as clearly illustrated by one participant:

Part of my incremental learning is of the 'keeping up with new developments' kind. There are new attitudes, new social conditions, etc. to keep up with.

(Interview \#3 Participant)

More explicitly articulated was the goal of maintaining an "active mind" in retirement and its relative value:

There needs to be something to do. For some people it might be just to knit something or watch TV, but having something of this level of engaging the mind I think is enormously valuable when you're retired. (Interview \#3 Participant)

Participants regularly referred to keeping a "healthy brain," "staying sharp," "being kept alive," and just maintaining "regular mental stimulation." One participant notably described the positive impact of engagement with others in their oPLNs and the potential contribution to social and mental health:

[J]ust [the] support and encouragement that I think we all need in our lives as you face difficult choices, [...] There is an immediate, an important contribution to emotional and physical health when people come online and say, offer, 'Have you tried this? The very personal experience that you're going through can be very important. [...] these are all important things to keep us positive in our lives. I cannot overstate the degree to which I find this very fulfilling and supportive to the way I want to be as a person. (Focus Group \#4, Participant \#1)

\subsubsection{Impacts on identity integrity}

Aspects of life and developmental transitions (e.g., retirement) were explicitly identified by participants. As such, specific facets such as re-establishing one's identity and "starting a new life" and "having something to offer" were salient topics of discussion:

[I] t's a whole new life I'm starting to build. I don't know quite how to do it. I'm just taking it one step at a time. (Interview \#4 Participant)

Absolutely [my online engagement ...] makes you feel that you still have something to offer. (Interview \#1 Participant)

Similarly, the importance of "identity integrity" on impacting mental health was deemed a necessary and healthy goal in retirement, especially as conjoined with the empowerment of maintaining an "engaged mind":

I think that when you're older, perhaps retired, sometimes you feel less of a person. You sort of lose your identity...You think "social anxiety"...but I think it can be huge when you're retired and you're trying to put yourself out there. (Interview \#1 Participant)

[T]he point of being kept alive at these conversations I think are very important. If nothing else it's a destination for people in our age group. Something to do doesn't quite capture it. [...] It's not like you have a clear direction. It's that you are keeping your mind open. 
(Interview \#3 Participant)

Equally important, given the potential positive impact of regular and meaningful personal interactions for one's well-being (Barbour, Clark, Jones, \& Veitch, 2012), the following excerpt captures the essential sentiment of the valuing this interpersonal contact and the reciprocal and supportive nature of their online communications with others in their oPLNs:

[E]veryone will say, you know, 'How are you? How did you enjoy your holidays?', and, 'I know you've been away, 'and, 'Did you have a good vacation?' So yeah it does mean there is an interest in who you are, what you are kind of thing. [...] It makes you feel comfortable in that environment and I also think it makes you feel comfortable that you could ask, 'Well I read this chapter, but what do you think about this chapter because I'm totally confused?'So, you don't feel threatened going to ask it, so there's a comfort level there. (Interview \#1 Participant)

The apparent establishment of rapport between and among other members of their oPLNs reinforces our conviction of its importance to create a safe and encouraging communication environment, bespeaking a level of "friendly connection" amongst peers. In other words, being a member of a supportive and non-threatening learning environment, where personal connections are established and valued is, in our opinion, a cornerstone of a mutually beneficial and mental health-promoting (Bassuk, Glass, \& Berkman, 1999) online learning ecosystem. The positive impact of having and maintaining relationships with others, to have a "support-network," is clearly identified as significantly impacting one's mental and physical well-being as one ages (Barbour, Clark, Jones, \& Veitch, 2001). These asynchronous, long-distance relationships, established via activity in their oPLNs, provided unique opportunities to be "in touch" with others and being supported through one's "learning ecosystem":

I've met really, really nice people that way...Like sometimes they're far away, but I've developed-I've really established relationships with people. I find my needs get met very quickly.

(Interview \#5 Participant)

[T]ime with their help and family or whatever or, that there's some disaster in their area. That those of us often send wishes and supportive messages that are not on a topic that isn't what brought us together. (Focus Group \#2, Participant \#1)

\section{Further Discussion}

While our brief sequential, embedded discussion of the findings presented above has utility in grounding local interpretations, an expanded elucidation is required. In other words, to enhance the explanatory power in "translating" our findings into a larger context of understanding, we will now discuss our findings within frameworks of theory and practice, thereby enabling increased confidence in any inferred conclusions postulated regarding the phenomenon of the impacts of informal, self-directed learning within online learning communities such as oPLNs. 


\subsection{Impact Value of Networked Learning}

The focus of this study was to examine how older retired adults create, maintain, and engage with their online personal learning networks (oPLNs). Conceptualizing oPLNs as any network of individuals and/or groups that use ICT tools and processes to communicate about their hobby or interest provided necessary operational definition flexibility. While there was logical variance regarding what social media tools were or were not included (e.g., Facebook vs. Twitter) in any participant's oPLN (Morrison et al., 2020), the anchoring concept was that they used the Internet to communicate with others and gather resources relevant to their particular hobby or interest. This reported phenomenon and the processes used to activate it are in line with networked learning theory (Asensio et al., 2000) and principles of heutagogy (Blaschke, 2012; Blaschke \& Hase, 2016) whereby technology-enhanced learning activities were initiated and animated not only by the ICT tools and processes, but, most importantly, by participants' interactions and exchanges with each other within that online environment. Essentially, for these participants, oPLNs became "ecologies of learning" (Brown, 2000; Fox, 2000). These learning ecologies were variable and provided unique learning contexts, with differing purposes, processes and content foci; within any such learning ecologies, variables might include: hybrid learning (i.e., online and offline), use of multimedia, multi-sourced resources, and the utilization of mobile devices to facilitate anytime/anywhere activity within and throughout the learning ecology.

\subsubsection{Impact Value of Networked Learning: Social and Mental Well-Being}

Under the "umbrella" concept of networked learning, as recipients of and contributors to their online network of learners, the findings indicate that online interaction, within their oPLNs, was clearly tied to a perception of connection with others, thus providing a sense of belonging and a positive social identity. It was also clear that these outcomes were valued impacts and elements of their online activity; our interpretation here is that significant "social capital" (Yu et al., 2010; Huysman et al., 2003; Oztok, 2012) was generated within the network of older adult learners. This finding should not come as a surprise given that $\mathrm{Lu}$, Yang and Yu (2013) indicate that "online learning facilitates social capital formation mostly in terms of the dimensions of community, trust, collective action and cooperation, communication, and sociability and inclusion" (p. 507), all of which align with our findings presented here. Similarly with Haslam, Cruwys and Haslam's (2014) findings, it is apparent from the data reported that, for many, such online engagement with the group members of their oPLNs provided distinct benefits in the perceived enhancement of their mental health. Moreover, these self-reports are not trivial and may point to additional speculations regarding the potential of online learning to augment social interaction among older adults and the "added value" of meaningful and reciprocal cognitive engagement with others.

\subsubsection{Impact value of networked learning: Obviating social isolation}

In a national longitudinal study examining loneliness, health and mortality in old age, Luo et al. (2012) concluded that "....a growing literature indicating that loneliness is a risk factor for morbidity and mortality..” (p. 907). Caciappo \& Caccioppo (2018) indicate that loneliness results in a $26 \%$ increase in the risk of premature mortality and that in industrialized countries 
around a third of people are affected by this condition; it is important to note that: "Income, education, sex, and ethnicity are not protective" (p. 4080). Importantly, the authors state that the effects of the condition of loneliness are "not attributable to some peculiarity of the character of a subset of individuals, they are a result of the condition affecting ordinary people" (p. 4080). So, while loneliness is often stigmatized, trivialized, or ignored within the rapidly growing population of older adults in industrialized countries, it is "emerging as a public health problem" (Cacioppo \& Cacioppo, 2018, p. 4080). Further, Rook (1984), as well as Donaldson and Watson (1996), claim that loneliness, experienced by older adults in particular, is a risk factor that can negatively affect mental and physical health; conversely, when a sense of social integration and/or emotional connection is realized (e.g., as per online engagement with others), a reduction in feelings of estrangement and concomitant loneliness can possibly be realized. Based on our findings, the conduit to increased cognitive health and well-being among older adults might rationally be speculated as a potential "antidote" to the negative effects of social isolation and loneliness on health and well-being in the older adult population. In other words, the active and regular engagement with the members of oPLNs around the goals of informal learning with others is one concrete resolution to at least some of the risk factors posed by social isolation and loneliness for older adults. Lubben and Gironda (2003), in their listing many of the possible definitions of "supportive social ties," reinforce the relevant and illustrative descriptors of the findings presented here, namely: "...the highly complex phenomenon of social relationship/ties has resulted in the construct being labeled as "social bond, social supports, social networks, social integration, social ties, meaningful social contacts, confidants, human companionships, reciprocity, guidance, information given, emotional support and organizational involvement" (Lubben \& Gironda, 2003 , p. 319). We conclude, then, that the intrinsically-motivated desire to learn from and with others within a socially-constructed online "ecosystem" of like-minded individuals, for the purposes of pursuing one's "passion" (i.e., hobby or interest) in one's retirement years may be a valuable source of social, mental and even physical well-being.

\section{Conclusion and Further Research}

This research presents a multitude of avenues available to researchers to further investigate the nature of online, informal learning amongst older adults. Details of such an extended investigation might include: the valuing of others in learning networks as resources that enhance the learning experience; collectively scaffolded group learning; connection to others with affiliated interests as a driving force for learner retention and satisfaction; and, the processes of curation and sharing of valued resources within online groups of older adults, to name but a few possible research trajectories. Finally, attitudes to and perceptions of independent, autonomous and self-directed informal learning and its benefits, including, as Ballatti, Black and Falk (2007) suggest, "the proposition that networks of relationships are a resource that can facilitate access to other resources of value to individuals or groups for a specific purpose" (p. 282) would be a distinct arena for further research.

While the data from this research is limited in scope and generalizability, it has provided confidence regarding speculations that further research regarding older adults who engage with others in online learning ecosystems may provide additional evidence regarding the 
general health benefits of such activities and processes. We would add that the further examination of the nature of informal, self-directed online learning for older adults is needed; specifically, it will be important to continue to investigate how an intrinsically-motivated desire to learn from and with other older adults, within a socially-constructed and technology-mediated online "learning ecosystem" (Bronfenbrenner, 1999), one reflective of the principles of heutagogy (Blaschke, \& Hase, 2016), may be a valuable and effective conduit and mechanism for countering social isolation and positively affecting the social, mental and physical well-being of older adults. In addition, this study and future research has significant implications in contributing to digital health and public health initiatives for policy makers to consider in addressing the needs and well-being of aging societies world-wide.

\section{References}

Asensio, M., Foster, J., Hodgson, V. \& McConnell, D. (Eds.) (2000). Networked Learning 2000: Innovative Approaches to lifelong Learning and Higher Education Through the Internet. Proceedings of the $2^{\text {nd }}$ International Conference, Lancaster University, 2000

Barbour, V., Clark, J., Jones, S., \& Veitch, E., (2012). Social relationships are key to health. PLoS Med. 7(8), e1000334. https://doi.org/10.1371/journal.pmed.1000334

Bassuk, S.S., Glass, T.A., Berkman, L.F., (1999). Social disengagement and incident cognitive decline in community-dwelling elderly persons. Ann. Intern. Med., 131, 165-173. https://doi.org/10.7326/0003-4819-131-3-199908030-00002

Blaschke, L. M. (2012). Heutagogy and lifelong learning: A review of heutagogical practice and self-determined learning. International Review of Research in Open and Distance Learning, 57-71. https://doi.org/10.19173/irrodl.v13i1.1076

Blaschke, L., \& Hase, S. (2016). Heutagogy: A Holistic Framework for Creating Twenty-First-Century Self-determined Learners. In M. M. Begoña Gros, Kinshuk (Ed.), The Future of Ubiquitous Learning (pp. 25-40). Springer Berlin Heidelberg. https://doi.org/10.1007/978-3-662-47724-3_2

Boyatzis, R. (1998). Transforming Qualitative Information: Thematic Analysis and Code Development. SAGE Publications, pp. 200.

Bronfenbrenner, U. (1999). Environments in developmental perspective: Theoretical and operational models. (pp. 3-28). American Psychological Association. https://doi.org/10.1037/10317-001

Brookfield, S. D. (1985). Understanding and Facilitating Adult Learning: A Comprehensive Analysis of Principles and Practices. Milton Keynes, UK: Open University Press, pp. 367.

Brown, J.S. (2000). Growing up digital: How the web changes work, education, and the ways people learn. Change Magazine, March/April, 11-20. https://doi.org/10.1080/00091380009601719

Cacioppo, J. T. \& Cacioppo, S. (2018). The growing problem of loneliness. The Lancet, 
391(1-229), 1480-1491. https://doi.org/10.1016/S0140-6736(18)30142-9

Campagne, D. M. (2019). Stress and perceived social isolation (loneliness). Archives of Gerontology and Geriatrics, 82, 192-199. https://doi.org/10.1016/j.archger.2019.02.007

Campell, K. (1999). The web: Design for active learning. Academic Technologies for Learning, Cordonline.net.

Candy, P. C. (1991). Self-direction for lifelong learning. San Francisco, CA: Jossey Bass.

Castaneda, L., \& Soto, J. (2010). Building personal learning environments by using and mixing ICT tools in a professional way. Digital Education Review, 18, 9-25.

Cornwell, E. (2009). Social disconnectedness, perceived isolation, and health among older adults. Journal of Health \& Social Behaviour, 50(1), 31-48. https://doi.org/10.1177/002214650905000103

Davis, M., \& Denning, K. (2000) 'Online Learning: Frontiers in the Creation of Learning Communities.' In Asensio, M., Foster, J., Hodgson, V. \& McConnell, D. (Eds.) Networked Learning 2000: Innovative Approaches to Lifelong Learning and Higher Education Through the Internet. Proceedings of the $2^{\text {nd }}$ International Conference, Lancaster University, 2000

Dickenson, A., \& Gregor, P. (2006). Computer use has no demonstrated impact on the well-being of older adults. International Journal of Human-Computer Studies, 64, 744-753. https://doi.org/10.1016/j.ijhcs.2006.03.001

Donaldson, J. M., \& Watson, R. (1996). Loneliness in elderly people: An important area for nursing. Research Journal of Advanced Nursing, 24, 952-959. https://doi.org/10.1111/j.1365-2648.1996.tb02931.x

Dorin, M. (2007). Online education of older adults and its relation to life satisfaction. Educational Gerontology, 33, 127-143. https://doi.org/10.1080/03601270600850776

Fernback, J. (1999). There is a there there: notes toward a definition of cybercommunity. In Jones, S. (Ed.) Doing Internet Research: Critical Issues and Methods for Examining the Net. Thousand Oaks: SAGE.

Fink, L. D. (2003). Creating significant learning experiences: An integrated approach to designing college courses. San Francisco, CA: Jossey-Bass.

Fox S. (2002). Studying Networked Learning: Some Implications from Socially Situated Learning Theory and Actor Network Theory. In: Steeples C., Jones C. (eds) Networked Learning: Perspectives and Issues. Computer Supported Cooperative Work. Springer, London. https://doi.org/10.1007/978-1-4471-0181-9_5

Garrison, D. R. (1997). Self-directed learning: Toward a comprehensive model. Adult Education Quarterly, 48(1), 18-33. https://doi.org/10.1177/074171369704800103

Glass, T. A., MendesDe Leon, C. F., Bassuk, S. S., \& Berkman, L. F. (2006). Social engagement and depressive symptoms in later life: Longitudinal findings. Journal of Aging 
and Health, 18(4), 604-628. https://doi.org/10.1177/0898264306291017

Godbey, G. (2003). Leisure in your life: An exploration. State College, PA: Venture Publishing.

Golden, J. (2009). Loneliness, social support networks, mood and well-being in community-dwelling elderly. International Journal of Geriatric Psychiatry, 24(7), 694-700. https://doi.org/10.1002/gps.2181

Hague, B.N., \& Loader, B.D. (Eds.) (1999) Digital Democracy: Discourse and Decision Making in the Information Age. London: Routledge.

Hernandez, B., Montaner, T., Sese, F. J., \& Urquizu, P. (2011). The role of social motivations in e-learning: How do they affect usage and success of ICT interactive tools? Computers in Human Behavior, 27, 2224-2232. https://doi.org/10.1016/j.chb.2011.07.001

Hasalam, C., Cruwys, T., \& Haslam, A. (2014). "The we's have it": Evidence for the distinctive benefits of group engagement in enhancing cognitive health in aging. Social Science \& Medicine, 120, 57-66. https://doi.org/10.1016/j.socscimed.2014.08.037

Hazer, O., \& Boylu, A. A. (2010). The examination of the factors affecting the feeling of loneliness of the elderly. Procedia: Social and Behavioural Sciences, 9, 2083-2089. https://doi.org/10.1016/j.sbspro.2010.12.450

Hernández-Encuentra, H., Pousada, M., \& Gómez-Zúñiga, B. (2009). ICT and Older People: Beyond Usability, Educational Gerontology, 35(3), 226-245. https://doi.org/10.1080/03601270802466934

Huysman, M. H., Cummings, S. R., \& Heeks, R. (2003). Knowledge and learning in online communities in development: A social capital perspective. Development Informatics, Working Papers Series, information, Logistics and Innovation, KIN Center for Digital Innovation, VU, Amsterdam: NL. https://doi.org/10.2139/ssrn.3477754

Jaramillo, J. A. (1996). Vygotsky's sociocultural theory and contributions to the development of constructivist curricula. Education, 117(1), 133-140.

Kawachi, I, Kennedy, B. P. \& Glass, R. (1999). Social capital and self-rated health: A contextual analysis. American Journal of Public Health, 89(8), 1187-1193. https://doi.org/10.2105/AJPH.89.8.1187

Kelly, J.R. (2012). Leisure (4thed.). Urbana, IL: Sagamore Publishing.

Kerry, W. (1962). The decline of pleasure. New York, NY: Simon \& Schuster.

Kraemer, H. C. (2015). Kappa Coefficient. Wiley StatsRef: Statistics Reference Online, https://doi.org/10.1002/9781118445112.stat00365.pub2

Lu, J., Yang, J., \& Yu, CS. (2013). Is social capital effective for online learning? Information \& Management, 50, 507-522. https://doi.org/10.1016/j.im.2013.07.009

Lubben, J., \& Gironda, M. (2003). Centrality of social ties to the health and well-being of 
older adults. In: Social Work and Health Care in an Aging Society: Education, Policy, Practice, and Research. (Berkman, B, \& Harootyan, L, Eds.), New York:NY, Springer, pp. 397.

Luo, Y., Hawley, L. C., Waite, L. J., \& Cacioppo, J. T. (2012). Loneliness, health, and mortality in old age: A national longitudinal study. Social Science \& Medicine, 74(6), 907-914. https://doi.org/10.1016/j.socscimed.2011.11.028

Marsick, V.I., \& Watkins, K. (1990) Informal and Incidental Learning in the Workplace. London: Routledge.

Merriam, S. B. (2001). Andragogy and self-directed learning: Pillars of adult learning theory. New Directions for Adult and Continuing Education, \#89, San Francisco, CA: Jossey-Bass. https://doi.org/10.1002/ace.3

Merriam, S. B. \& Bierema, L. (2014). Adult Learning: LInking Theory and Practice. San Francisco, CA: Jossey-Bass.

Merriam, S. B., \& Kee, Y. (2014). Promoting community well-being: The case for lifelong learning for older adults. Adult Education Quarterly, 64(2), 128-144. https://doi.org/10.1177/0741713613513633

Mesirow, J. (1985). A critical theory of self-directed learning. In S. Brookfield (Ed.), Self-directed learning: From theory to practice (pp. 17-30). New Directions for Continuing Education, \#25. San Francisco: Jossey-Bass. https://doi.org/10.1002/ace.36719852504

Morrison, D. \& McCutcheon, J. (2019). Empowering older adults' informal, self-directed learning: The potential of online personal learning networks. Research and Practice in Technology Enhanced Learning, 14(10). https://doi.org/10.1186/s41039-019-0104-5

Morrison, D., Litchenwald,, K. \& Tang, R. (2019). Extending the online focus group method using web-conferencing to explore older adults' online learning. International Journal of $\begin{array}{llll}\text { Research and } \text { Method in } & \text { Education, } 92 .\end{array}$ https://doi.org/10.1080/1743727X.2019.1594183

Morrison, D., Litchenwald, K., \& Krystkowiak, H. (2020). Older Adults' Use of Online Personal Learning Networks to Construct Communities of Learning. Journal of Studies in Education, 10(1), 18-43. https://doi.org/10.5296/jse.v10i1.16010

Neulinger, J. (1981). The psychology of leisure. Springfield, IL: Charles C. Thomas.

Nowell, L. S., Norris, J. M., White, D. E., \& Moules, N. J. (2017). Thematic analysis: Striving to meet the trustworthiness criteria. International Journal of Qualitative Methods, 16, 1-13. https://doi.org/10.1177/1609406917733847

Oztok, M. (2012). Tacit knowledge in online learning: Community, identity and social capital. Technology, Pedagogy and Education, 21-36. https://doi.org/10.1080/1475939X.2012.720414

Pieper, J. (1952). Leisure: The basis of culture (A. Dru, Trans.). New York, NY: Pantheon 
Books.

Rapaport, R., \& Rapaport, R.N. (1975). Leisure and the family life cycle.Boston, MA: Routledge \& Kegan Paul.

Resnick, L. B. (1991). Shared cognition: Thinking as social practice. In L. B. Resnick, J. M. Levine, \& S. D. Teasley (Eds.), Perspectives on socially shared cognition (1-20). Washington, DC: American Psychological Association. https://doi.org/10.1037/10096-018

Rook, K. S. (1984). Research on social support, loneliness and social isolation towards an integrated review of personality. Social Psychology, 5, 239-264.

Russell, R.V. (2013). Pastimes: The context of contemporary leisure (5th ed.). Urbana, IL: Sagamore Publishing.

Shapira, N., Barak, A., \& Gal, I. (2007). Promoting older adults' well-being through Internet training and use. Aging and Mental Health, 11(5), 477-484. https://doi.org/10.1080/13607860601086546

Sharma, P., \& Hannafin, M. J. (2007). Scaffolding in technology-enhanced learning environments. Interactive Learning Environments, 15(1), 27-46. https://doi.org/10.1080/10494820600996972

Shima Sum, S. R., Mathews, M., Ian Hughes, I., \& Campbell, A. (2008). Internet use and loneliness in older adults. CyberPsychology \& Behavior, 11(2), 208-211. https://doi.org/10.1089/cpb.2007.0010

Stokowski, P.A. (1994). Leisure in society: A network structural perspective. New York, NY: Villiers.

Sutherland, R., Armstrong, V., Barnes, S., Brawn, N., Gall, M., ... John, P. (2004). Transforming teaching and learning: Embedding ICT into everyday classroom practices. Journal of Computer Assisted Learning, 20, 413-425. https://doi.org/10.1111/j.1365-2729.2004.00104.x

Theeke, L. A. (2009). Predictors of loneliness in U.S. adults over age sixty-five. Archives of Psychiatric Nursing, 23(5), 387-396. https://doi.org/10.1016/j.apnu.2008.11.002

Yu, Y. A., Tian, S.W., Vogel, D., \& Kwok, R. C. (2010). Can learning be virtually boosted? An investigation of online social networking impacts. Computers \& Education, 55(4), 1494-1503. https://doi.org/10.1016/j.compedu.2010.06.015

Verduin, J.R., \& McEwen, D.N. (1984). Adults and their leisure: The need for lifelong learning. Springfield, IL: Charles C. Thomas.

Victor, C. R. (2005). The prevalence of and risk factors for loneliness in later life: A survey of older people in Great Britain. Ageing and Society, 25(3), 357-375. https://doi.org/10.1017/S0144686X04003332 